\title{
Synthesis and tribological properties of $\mathrm{WSe}_{\mathrm{x}}$ films prepared by
}

\section{magnetron sputtering}

\author{
S. Dominguez-Meister, A. Justo, J. C. Sanchez-Lopez* \\ Instituto de Ciencia de Materiales de Sevilla (CSIC-Univ. Sevilla), Avda. Américo \\ Vespucio 49, 41092-Sevilla, Spain.
}

\begin{abstract}
$\mathrm{WSe}_{\mathrm{x}}$ films with variable $\mathrm{Se} / \mathrm{W}$ ratio were deposited by non-reactive r.f. magnetron sputtering from $\mathrm{WSe}_{2}$ target changing the applied d.c. pulsed bias conditions and substrate temperature. The structural and chemical properties were measured by crosssectional scanning electron microscopy (X-SEM), energy dispersive analysis (EDX), Xray diffraction (XRD), Raman and X-ray photoelectron spectroscopy (XPS).The tribological properties were measured in ambient air $(\mathrm{RH}=30-40 \%)$ and dry nitrogen by means of a reciprocating ball-on-disk tribometer. A clear correlation was found between the $\mathrm{Se} / \mathrm{W}$ ratio and the measured friction coefficient displaying values below 0.1 (in ambient air) and 0.03 (in dry $\mathrm{N}_{2}$ ) for ratios $\mathrm{Se} / \mathrm{W} \geq 0.6$ as determined by electron probe microanalysis (EPMA). The results demonstrated that notable tribological results could be obtained even in ambient air (friction $\leq 0.07$ and wear rate $\approx 10^{-7} \mathrm{~mm}^{3} / \mathrm{Nm}$ ) by controlling the film microstructure and chemical composition. By incorporating carbon, wear and chemical resistance can be gained by formation of non-stoichiometric carbides and/or alloying into the defective $\mathrm{WSe}_{\mathrm{x}}$ hexagonal structure. The existence of a $\mathrm{WSe}_{2}$ rich interfacial layer (either on the ball scar or embedded in the film track) was evidenced by Raman in low friction conditions. The improvement in tribological performance is therefore obtained by means of layered $\mathrm{WSe}_{\mathrm{x}}$, the formation of gradient composition from metallic $\mathrm{W}$ (hard) to $\mathrm{WSe}_{2}$ (lubricant) and carbon incorporation.
\end{abstract}

${ }^{*}$ Corresponding author: jcslopez@icmse.csic.es 
Keywords: chalcogenides; friction; sputtering; Raman spectroscopy and scattering; microstructure; wear

\section{Introduction}

Transition metal sulfides $\left(\mathrm{MoS}_{2}, \mathrm{WS}_{2}\right)$ are well known for their lubricant properties, however, their application is limited to vacuum or dry environments. Increased wear resistance and load bearing capacity has been reported by alloying with metals ( $\mathrm{Ti}, \mathrm{Au}$, $\mathrm{Pb}, \mathrm{Ni}, \mathrm{Cr}$ ) [1] or non-metals ( $\mathrm{N}$ or carbon) [2]. As alternative, nanoscale multilayer (metal/MoS 2 [3], $\mathrm{MoS}_{2} / \mathrm{WS}_{2}$ [4]) or nanocomposites films, with mixed hard and soft lubricant phases $\left(\mathrm{MoS}_{2} / \mathrm{WC}\right.$ [5]; $\mathrm{WS}_{2} / \mathrm{WC} / \mathrm{DLC}$ [6]; TiN/MoS ${ }_{\mathrm{x}}$ [7]; $\mathrm{TiCrBN} / \mathrm{WSe}_{\mathrm{x}}[8]$, $\left.\mathrm{WS}_{2} / \mathrm{ZnO}[9]\right)$ have been also studied in the past. One of the most studied systems have been the transition metal dichalcogenides mixed with carbon by Polcar \& Cavaleiro by co-sputtering of the metal sulfides or selenides with graphite $[10,11]$. In particular, in the case of carbon, for $\mathrm{C}$ contents up to $\approx 40$ at. $\%$, an increased hardness and oxidation resistance of these materials during sliding was reported, permitting friction around 0.20.3 in O-containing and humid environments [12]. The coatings exhibited a nanocomposite structure composed of platelets of the metal dichalcogenides embedded in a C-rich amorphous matrix. Metal selenides are less studied than sulfides although they have been also object of intense study due to their self-lubricant properties [13-18], applications in photovoltaics [19] or ultralow thermal conductivity [20]. They have similar layered crystal structure although with higher axial ratio of lattice parameters which facilitates relative motion between layers [21]. They exhibit lower average friction coefficients [10] and have demonstrated to be less sensitive to moisture in the environment $[10,13,15]$. Nevertheless, they show similar drawbacks than their metal sulfides: low hardness, low adhesion to the substrate and lacking bearing capacity as 
well as high wear rate and friction coefficient in humid air. As metal, W is preferred to Mo as $\mathrm{WO}_{3}$ is slightly more protective than $\mathrm{MoO}_{3}$ and provides lower friction coefficient (0.2-0.3 vs. 0.5-0.6, respectively) [22]. In this work, at a first attempt the tribological behaviour of pure $\mathrm{WSe}_{\mathrm{x}}$ films, without intentional addition of dopants, prepared by magnetron sputtering is studied. With the aim of reinforcing the wear resistance and load-bearing capacity of the coatings, microstructure and chemical composition (gradient layer or WC inclusions) are tried. The detailed characterization has enabled to establish relationships between synthesis conditions, microstructure, chemical composition and properties.

\section{Materials and methods}

The $\mathrm{WSe}_{\mathrm{x}}$ coatings were prepared by radio frequency (r.f.) magnetron sputtering at $13.56 \mathrm{MHz}$ in an Ar atmosphere $\left(5 \times 10^{-3} \mathrm{mbar}\right)$ of $\mathrm{WSe}_{2}$ target (Kurt and Lesker, $99.5 \%$ purity, 2 " diameter). The deposition process started with resistive heating of the chamber to reach a base pressure better than $1 \times 10^{-6}$ mbar, followed by a plasma etching of the substrates in Ar atmosphere at $-350 \mathrm{~V}$ direct current (d.c.) pulsed bias. Four samples were prepared varying the synthesis conditions (applied bias, substrate temperature and sputtering power) as summarized in Table 1. The first $\mathrm{WSe}_{\mathrm{x}}$ film was prepared without intentional heating of the substrate at floating potential. For the following cases, a gradient d.c. pulsed bias was applied to the substrate with the aim of modulating the chemical and mechanical properties from the bottom (W-rich, hard) to the top (Se-rich, soft and lubricant). The pulse conditions were set at $250 \mathrm{kHz}$ of frequency, $1616 \mathrm{~ns}$ of duration $(60 \%$ duty cycle) and $25 \mathrm{~W}$ of power. The process is carried out in 6 steps, decreasing the power at $5 \mathrm{~W} / \mathrm{h}$ and finalizing with one hour at zero bias. To evaluate the influence of heating, two samples were grown at $250{ }^{\circ} \mathrm{C}$ while 
in the others the temperature did not rise above $40-70^{\circ} \mathrm{C}$ by effect of the plasma. Finally, with the aim of reinforcing the mechanical and tribological properties, the incorporation of WC phase by additional sputtering of a WC target (Testbourne Ltd., 99.5\% purity, 2" diameter) was tried in the last sample. The magnetron heads are tilted $45^{\circ}$ in respect to the substrate normal and placed 5 and $10 \mathrm{~cm}$ above the holder for $\mathrm{WSe}_{2}$ and $\mathrm{WC}$ target respectively. The coatings were deposited on $\mathrm{Si}$ (100) substrates and the total thicknesses were found to vary between 0.9 to $1.8 \mu \mathrm{m}$.

The crystal structure of the films was examined by grazing incidence X-ray diffraction (XRD) using an angle of $5^{\circ}$ and $\mathrm{Cu} \mathrm{K \alpha}$ radiation in a Siemens D5000 diffractometer with parallel beam geometry. A step size of $0.02\left(2 \theta^{\circ}\right)$ with $10 \mathrm{~s}$ per point were used.

A JEOL JXA-8200 electron probe microanalysis (EPMA) instrument at $15 \mathrm{kV}$ was used to determine the chemical composition of the samples in planar views.

Scanning electron microscopy (SEM) data were recorded in a FEG Hitachi S5200 microscope operating at $5 \mathrm{kV}$.

Raman spectra measurements $\left(200-1800 \mathrm{~cm}^{-1}\right)$ were carried out with a LabRAM (Horiba Jobin Yvon) spectrometer equipped with a true confocal microscope, a chargecoupled device detector and a He-Ne laser $(532 \mathrm{~nm})$ working at $2.5 \mathrm{~mW}$ to avoid sample damaging. All the samples were analyzed with $100 \mathrm{~s}$ exposure times and aperture openings of $100 \mu \mathrm{m}$ using a $50 \times$ magnification.

XPS measurements were carried out using a Thermo Scientific K-Alpha ESCA instrument equipped with aluminium $\mathrm{K}_{\alpha 1,2}$ monochromatized radiation at $1486.6 \mathrm{eV} \mathrm{X}$ ray source. Neutralization of the surface charge was performed by using both a low energy flood gun (electrons in the range 0 to $14 \mathrm{eV}$ ) and a low energy Argon ions gun ( 0 to $30 \mathrm{eV}$ ). Photoelectrons were collected from a take-off angle of $90^{\circ}$ relative to the 
sample surface. The measurement was done in a constant analyser energy mode (CAE) with $100 \mathrm{eV}$ pass energy for survey spectra and $20 \mathrm{eV}$ pass energy for high resolution spectra. Charge referencing was done by setting the binding energy of $\mathrm{C} 1 \mathrm{~s}$ photoelectron peak from adventitious carbon at $285.0 \mathrm{eV}$. Surface elemental composition was determined using the standard Scofield photoemission cross sections using a Shirley background subtraction. A surface cleaning was carried out by $\mathrm{Ar}^{+}$ sputtering at a voltage of $1 \mathrm{kV}$ during $60 \mathrm{~s}$ in order to remove the surface contamination and oxidation.

Nanoindentation experiments were performed with a MTS Nanoindenter II XP using the continuous stiffness measurement (CSM) technique. All tests were carried out at room temperature with a diamond Berkovich (three-sided pyramid) indenter tip. The load-displacement data obtained were analyzed using the method of Oliver and Pharr [23] to determine the hardness and the elastic modulus as a function of the displacement of the indenter. The estimation of both properties was done in the region in which the indentation depth did not exceed $10-15 \%$ of the coating thickness disregarding the initial points affected by tip defects and surface roughness.

The tribological properties of the coatings were evaluated by reciprocating friction tests in unlubricated sliding against $100 \mathrm{Cr} 6$ steel $6-\mathrm{mm}$ balls in ambient air, with relative humidity between $30-40 \%$ and dry nitrogen $(<8 \% \mathrm{RH})$. The test parameters were set to an applied load of $2 \mathrm{~N}$ (corresponding to a maximum initial Hertzian contact pressure of around $1 \mathrm{GPa}$ ), a linear speed of $2 \mathrm{~mm} / \mathrm{s}$, a stroke length of $2 \mathrm{~mm}$ and 2500 cycles of duration. Normalized wear rates $\left(\mathrm{mm}^{3} / \mathrm{Nm}\right)$ were evaluated from cross-sectional profiles taken across the disk-wear track using stylus profilometry.

\section{Results and discussion}




\subsection{Chemical and structural characterization}

The chemical composition of the $\mathrm{WSe}_{\mathrm{x}}$ coatings as determined by EPMA is summarized in Table 1. By establishing the Se/W ratios it can be noted that all the $\mathrm{WSe}_{\mathrm{x}}$ films are sub-stoichiometric with $\mathrm{x}$ values ranging from 0.7 to 1.6. This depletion in selenium is probably caused by differences in the scattering cross-sections in the gas phase, sticking coefficients and/or preferential re-sputtering phenomena between Se and W. Similar trend has been reported previously in W-S-C, W-Se-C, Mo-Se-C systems $[11,17]$ and $\mathrm{WSe}_{\mathrm{x}}[8]$ although stoichiometric $\mathrm{WSe}_{2}$ could be obtained under certain conditions [18]. The existence of vacancies in the structure can facilitate the incorporation of oxygen. Carbon and oxygen contamination was found in the level of 510 at. $\%$ originated by air exposure. Its character is mainly superficial as it was demonstrated by XPS survey after sputtering (Fig. 1a) except sample WSeC where carbon was intentionally incorporated using a WC target. The presence of oxygen in metal chalcogenides is usual due to the sensitivity of these materials to air exposure as has been previously reported by many authors but it decreases noticeably after sputtering $[8,11,17]$. It is also likely that part of the oxygen is captured during synthesis due to the porous nature of the $\mathrm{WSe}_{2}$ target. The $\mathrm{Se} / \mathrm{W}$ ratios were also calculated by XPS before and after surface cleaning (shown in Fig.1b). The values are found higher before $\mathrm{Ar}^{+}$sputtering as the cleaning etching induced a marked relative diminution of Se over W. For this reason we will therefore consider the photoelectron peaks without sputtering although the oxide components are present. Fig. 2a shows the XPS photoelectron peaks for Se 3d and W $4 \mathrm{f}$ of the as-deposited samples. The doublet Se 3d appears situated at 55.4 and $54.7 \mathrm{eV}$ in agreement with the values of a tungsten selenide 
$[8,17]$. Two bonding states are distinguished for the $\mathrm{W}$ atoms. The $\mathrm{W} 4 \mathrm{f}_{5 / 2}$ and $\mathrm{W} 4 \mathrm{f}_{7 / 2}$ peaks at 38.3 and $36.2 \mathrm{eV}$ match well with $\mathrm{WO}_{3}$ and are due to oxide contamination. The $\mathrm{W}$ peaks of the second doublet are situated at 34.6 and $32.4 \mathrm{eV}$ and can be ascribed to the tungsten selenide $[8,17]$. The relative higher incorporation of Se in the sample WSe-3 is clearly noticed by comparison of the peak intensities of both elements. The samples WSe-1 and $\mathrm{WSeC}$ corresponding to the film prepared in the absence of bias and with incorporation of WC phase respectively are more oxidized in surface. The existence of carbon atoms inside the coating for the WSeC sample was demonstrated by $\mathrm{Ar}^{+}$etching at $3 \mathrm{kV}$ during 120s. In Fig. 2b, the C1s XPS region after sputtering denotes a permanent component situated at 283.9 that is not merely superficial. This is indicative that during sputtering of WC target, carbon has been incorporated into the $\mathrm{WSe}_{\mathrm{x}}$ structure, probably in lattice defects and boundary regions, as the binding energy is between that of hydrocarbon $(285.0 \mathrm{eV})$ and tungsten carbide $(283.5 \mathrm{eV})[17,24]$.

The microstructure and chemical composition of the films was studied in crosssectional views by SEM and EDX analysis, respectively (Fig. 3). The sample WSe-1 grown without bias at room temperature shows a fine granular texture with low surface roughness. The chemical composition is constant along the thickness with a $\mathrm{Se} / \mathrm{W}$ ratio measured of approximately 1:1. The application of a gradient modulated bias (WSe-2) introduces noticeable changes. The morphology is formed by three sublayers of approximately 350,200 and $350 \mathrm{~nm}$, from the bottom to the top surface, respectively. The chemical composition is gradually changing from metallic W (columnar); Se/W close to 0.5 (fine granular); Se/W around 1.1 (granular). When the modulated bias is applied with substrate heating (WSe-3) although the Se/W ratio increases up to 1.6 the structure appears more opened. After the initial columnar region, the morphology branches out forming a broccoli-like structure. This behaviour can be understood by an 
increased selenium surface diffusion and adatom mobility induced by temperature. In the sample $\mathrm{WSeC}$, prepared by co-sputtering of $\mathrm{WSe}_{2}$ and $\mathrm{WC}$, a marked double-layer is differentiated, formed by a dense tungsten-rich region followed by a second glancing columnar microstructure with Se/W close to unity. The incorporation of carbon is not very high, below 15 at.\%. The surface roughness is also observed to increase significantly up to $\mathrm{R}_{\mathrm{a}} \approx 19 \mathrm{~nm}$ vs. $2-4 \mathrm{~nm}$ in the remaining cases (cf. Table 1). Again, the differences in scattering kinetics between $\mathrm{W}$ and $\mathrm{C}$ atoms are reflected in a preferential incorporation of tungsten in respect to the second. The tilted open columnar-like microstructure and increased roughness responds to a shadowing effect and a diminution of the mean energy of the energetic species, reducing substantially surface adatom mobility.

XRD diffractrograms measured in grazing angle incidence are shown in Fig. 4. The positions for main peaks of $\mathrm{W}$ (PDF \# 4-0806), $\mathrm{WSe}_{2}$ (PDF \# 87-2418) and $\mathrm{W}_{2} \mathrm{C}$ (PDF \# 35-776) references are marked in the same plot. The WSe-1 film shows a very broad band between 30 and $50^{\circ}$ indicative of a significant amorphous character. The WSe-2 film only shows a very intense peak at $39.9^{\circ}$ characteristic of (110) of W but no peaks can be detected for the $\mathrm{WSe}_{2}$ compound. This result confirms the conclusion obtained from the cross-sectional analysis by SEM/EDX where a transition from columnar W-rich to amorphous $\mathrm{WSe}_{\mathrm{x}}$ structure was observed. The radiative heating of the substrates in the sample WSe-3 brought an increased crystallization of the $\mathrm{WSe}_{2}$ phase with maxima centred at $32.3,38.6$ and $57.4^{\circ}$. The first and third peak can be assigned to (101) and (112) family of planes of $\mathrm{WSe}_{2}$. The second peak appear as a very broad band due to the overlapping of (103) of $\mathrm{WSe}_{2}$ and (110) of $\mathrm{W}$ underneath. The simultaneous sputtering of a WC target led to a notable diminution of crystallinity in the sample WSeC. Two broad and low reflections are denoted at 32.2 and $57.5^{\circ}$ originated 
by (101) and (112) of $\mathrm{WSe}_{2}$. The more intense signal corresponds to a broad band centred at $39.7^{\circ}$ that could be the result of sum of selected reflections from $\mathrm{W}, \mathrm{WSe}_{2}$ and $\mathrm{W}_{2} \mathrm{C}$ phases. This last result points to a degradation of the crystallinity by the cosputtering of the WC target, contrary to what was aimed.

Raman spectra of the samples are shown in Fig. 5 compared with the spectrum obtained for the $\mathrm{WSe}_{2}$ target. The observations support the conclusions obtained from $\mathrm{XRD}$ analysis. The most characteristic features are a narrow peak measured at $\sim 258 \mathrm{~cm}^{-}$

${ }^{1}$ with a shoulder extending over 165 to $220 \mathrm{~cm}^{-1}$. The spectrum of the $\mathrm{WSe}_{2}$ target is characterized by an intense peak at $250 \mathrm{~cm}^{-1}[8,25]$ and some small bands at 176,375 , 398 and $500 \mathrm{~cm}^{-1}$, as shown in the inset. The intensity of the main peak is marked in the samples prepared at $250^{\circ} \mathrm{C}$ while decreases noticeably in the case of room temperature deposition. The WSeC film, prepared by co-sputtering of $\mathrm{WC}$ and $\mathrm{WSe}_{2}$ phases, has shown a diminution of the $\mathrm{WSe}_{2}$ features indicating a less ordered structure. Besides, there was no evidence of induced structural arrangement of $\mathrm{WSe}_{2}$ by application of the modulated bias (WSe-2 vs. WSe-1).

\subsection{Tribological and mechanical characterization}

The hardness and Young modulus values of the four coatings are displayed in Fig. 6a. The hardness values are around 4-5 GPa and the elastic moduli between 70-90 GPa comparable with the values reported in the literature for WSeC films [11] and much better than bulk materials whose hardness values are lower than $0.5 \mathrm{GPa}$ [4]. Best mechanical properties and $\mathrm{H} / \mathrm{E}$ ratio are obtained for sample WSe-2 with the trilayer structure and poorest for the "broccoli-like" one (WSe-3). Incorporation of WC phase led to a slight hardness increase as compared to WSe-3 but not significant perhaps due to the lack of crystallinity. The hardness value is the result of a sum of factors 
(morphological, crystallinity, phase composition). In view of the nanocrystalline or amorphous character of all the samples, the behaviour is rather influenced by the morphological and chemical composition aspects. The WSe- 2 film is constituted by a stack of well-packed layers with increased hardness. The mechanical response of this packed system can be compared to a spring whose stiffness is increasing as the tip penetrates further into the film as can be observed in Fig. 6b. The samples grown with heating (WSe-3 and $\mathrm{WSeC}$ ) however exhibit lower hardness and their curves tend to stabilize at about 150 and $350 \mathrm{~nm}$ respectively. This is a consequence of the obtained open and rougher structures as compared to dense flat layered morphologies obtained at room temperature.

The tribomechanical properties were firstly measured in ambient air $(30-40 \% \mathrm{RH})$ for a complete series of $\mathrm{WSe}_{\mathrm{x}}$ samples (including the four detailed in this work and additional ones) with $\mathrm{Se} / \mathrm{W}$ ratios ranging from 0 to 1.6 (as measured by EPMA). Figure 7 plots the dependence of the average friction coefficient with the Se/W ratio. An exponential decay is observed as the content of selenium in the film composition increases. A threshold value of $\sim 0.6$ is found to be sufficient to reduce the friction below 0.1 even in ambient air. It is therefore demonstrated that it is not necessary to achieve the stoichiometric $\mathrm{WSe}_{2}$ to exhibit an ultralow friction coefficient. The achievement of the low friction is probably linked to the development of sufficient lamellae of Se-W-Se hexagonal basal planes that slip easily in the contact due to the weak Van der Waal's forces among them.

The evolution of the friction coefficient with the number of sliding cycles is displayed in Fig. 8 for the WSe-2 film measured in ambient air and dry nitrogen atmospheres. The average friction coefficient after a running-in period reaches a steadystate very quickly at around 0.07 and 0.03 for air and nitrogen, respectively. Fig. 9 
illustrates the differences in the morphology of the contact regions as a function of the nature of the environment. In ambient air, the formation of a homogeneous transfer film and the presence of loose debris on the ball scar are clearly denoted by removal of material from the initial film. The wear track appears very smooth with some detached particles at the end of the track. However, in dry nitrogen, the adhesion of "third-body" material onto the ball is less marked while the wear tracks are covered by smeared debris material. The material transfer to the rider in ambient air may be influenced by chemical wear. Oxygen and water molecules can enter the surface, react with or otherwise weaken it, and cause material to be released. In the case of nitrogen, the detached particles remain in the interface either imbedded in the surface or as free particles. This interfacial layer, as transfer layer on the ball or tribolayer in the track, formed in ambient air and dry nitrogen, respectively, is able to accommodate sliding and adsorb deformation energy, resulting in low friction and reduced wear of the counterfaces.

The friction values measured for the four samples together with the film wear resistances are shown in Fig. 10 and Fig. 11 for both types of surrounding atmospheres. In ambient air, the friction coefficients are not very dependent on the synthesis conditions showing values ranging from 0.05-0.07. These values are lower than transition metal dichalcogenides alloyed with carbon when measured in humid air $(0.1$ to 0.25 at $\mathrm{RH} \sim 50 \%$ ) [10]. In these compounds the existence of a $\mathrm{WSe}_{2}$ tribolayer in the sliding contact regardless on the sliding conditions is demonstrated providing low friction [11]. However, it is important to emphasize here that a more ordered structure does not necessary render lower friction. According to the Raman and XRD spectra of the initial films, the most ordered $\mathrm{WSe}_{2}$ structure corresponds to WSe-3 but exhibits an average friction coefficient comparable to that obtained with more amorphous films. 
That is because the atomic planes or platelets will self-align parallel to the surface in the friction contact as demonstrated by TEM examination of contact interfaces of randomly oriented $\mathrm{MoS}_{2}$ [26] and $\mathrm{MoSe}_{2}$ [27]. The wear rates however exhibit different values depending on the synthesis conditions ranging from $2 \times 10^{-5} \mathrm{~mm}^{3} / \mathrm{Nm}$ for the unbiased non-heated sample (WSe-1) to $3 \times 10^{-7} \mathrm{~mm}^{3} / \mathrm{Nm}$ for the sample WSe-2 (modulated bias). Both coatings exhibit similar Se/W ratios so the different wear resistance can be attributed to a higher mechanical strength of the second. Indeed the profile measured after finishing the test for the WSe-1 revealed that the coating was completely worn out probably influenced by an insufficient adhesion to the substrate. This result evidences the importance of the modulated bias to obtain a gradual variation in chemical composition and mechanical properties providing good adhesion to the substrate together with excellent tribological performance. By this way, a low shear stress is generated at the contact and the $\mathrm{W}$-rich underlayer provides a good mechanical support to guarantee a low contact area. The importance of a hard underlayer has been previously pointed out to be essential for extreme low friction $[13,14]$. Heating the samples during growth promotes a change of the film morphology that appears less resistant than the observed packed trilayer in WSe-2. The WC phase incorporation, however, represents a certain improvement of the wear resistance as compared to the WSe-3 performance. This result could be attributed to a higher mechanical strength, as measured by nanoindentation, or better chemical resistance. According to the chemical bonding determined by XPS and XRD data, carbon can be incorporated in the form of $\mathrm{W}_{2} \mathrm{C}$ nanocystals forming $\mathrm{WSe}_{\mathrm{x}} / \mathrm{W}_{2} \mathrm{C}$ nanocomposites or by alloying of $\mathrm{C}$ into the defective $\mathrm{WSe}_{\mathrm{x}}$ structure.

In order to discriminate the influence of the environment in the tribological behaviour similar friction tests were carried out in dry nitrogen $(\mathrm{RH}<8 \%)$. Figure11 
depicts the obtained friction and wear rate values for the set of films in this atmosphere. The friction coefficient and wear rates are comparatively similar to those measured in ambient air with average friction ranging from 0.03 to 0.09 and wear rates from $1 \times 10^{-5}$ to $1 \times 10^{-6} \mathrm{~mm}^{3} / \mathrm{Nm}$. The best wear performance is in this case obtained with the sample WSeC prepared with modulated bias, under heating and $\mathrm{WC}$ incorporation. The reduced sensitivity to air humidity can be explained if the sliding process is predominant driven by the properties of the metal chalcogenide tribolayer as pointed by Polcar et al. [27]. In the case of ambient air, the $\mathrm{WSe}_{\mathrm{x}}$ material agglomerates in the contact region, forming a transfer film, which prevents abundant oxidation of the dangling bonds of the original transition metal platelets. In dry nitrogen, the shear occurs between the planes parallel to the surface inside the smeared debris material. As a consequence, the friction is not so much affected by the surrounding environment as reported previously $[10,13,15]$.

Post-Raman analysis was undertaken on both counterfaces (film track and ball scar) to get knowledge about the physico-chemical transformations induced during friction in ambient air and dry nitrogen. Special care has to be taken during measurements by filtering the incident laser beam since fine material is very prone to oxidation and graphite formation. Fig. 12a shows the spectra obtained from the film track for the tests run in air. The first observation is the narrowing of the characteristic peak of W-Se bonds at $260 \mathrm{~cm}^{-1}$ as compared to the spectra of the initial films, particularly for the initially more disordered samples (WSe-1 and WSe-2). This supposes an induced structural arrangement of the $\mathrm{WSe}_{2}$ structure upon friction. The characteristic peak of crystalline silicon at $520 \mathrm{~cm}^{-1}$ is observed in the wear track of WSe-1 film from uncoated areas of the substrate. The analysis of parts of the material adhered to the ball is shown in Fig. 12b. In some cases, new bands originated by film oxidation and contamination are observed over the typical spectrum of $\mathrm{WSe}_{2}$. Thus, the 
broad band extending from 600 to $800 \mathrm{~cm}^{-1}$ is situated in the region of $\mathrm{W}-\mathrm{O}-\mathrm{W}$ stretching bonds of $\mathrm{WO}_{3}$. The second peak situated in the proximity of $\sim 960 \mathrm{~cm}^{-1}$ is characteristic of $\mathrm{W}=\mathrm{O}$ bonds formed at the periphery of $\mathrm{WSe}_{\mathrm{x}}$ or inside tungsten oxides hydrates [28,29]. The peaks at 1375 and $1595 \mathrm{~cm}^{-1}$ are the typical D and G bands of disordered carbon phases, respectively. It is important to emphasize that it is always possible to find points whose Raman spectra match perfectly with the initial $\mathrm{WSe}_{\mathrm{x}}$ film in all ball scars. The selected spectra are chosen on a basis of examples of the type of chemical modifications produced by friction. The spectra obtained from the loose debris (not shown) always demonstrate a higher contribution of the oxide phases and carbon contamination. When comparing the spectrum obtained for both counterfaces in dry nitrogen (cf. Fig. 13a and 13b) it is concluded that the spectra are essentially formed by the same types of bands although material adhered to the ball are less oxidized than those obtained in air. Secondly, the ordering phenomena of the initial $\mathrm{WSe}_{\mathrm{x}}$ layers are more evident in dry environment as can be concluded from the development of the peak at $\sim 250 \mathrm{~cm}^{-1}$ and the associated bands at 375 and $515 \mathrm{~cm}^{-1}$ owing toWSe 2 .

\section{Conclusions}

The preparation of stoichiometric $\mathrm{WSe}_{2}$ films by magnetron sputtering is difficult due to different scattering in the gas phase, sticking coefficient and re-sputtering effects of Se and $\mathrm{W}$ atoms. However, in this work we have demonstrated that is possible to design tailored lubricant $\mathrm{WSe}_{\mathrm{x}}$ thin films by modifying the microstructure and chemical composition using a time-dependent variation of the applied bias voltage. A gradient bias results beneficial for the improvement of the adhesion to the substrate, by creating an initial W-rich zone, and lubricant properties, by generation of a top region rich in selenium. Furthermore, it is also beneficial to have a gradual transition in mechanical 
properties (hard underlayer to soft lubricious region). Mechanical properties are much improved as compared to bulk materials and low friction coefficients $(0.03-0.07)$ are obtained either in air or nitrogen for $\mathrm{WSe}_{\mathrm{x}}$ films with $\mathrm{x}>0.6$. Friction induces structural re-ordering of the initial amorphous $\mathrm{WSe}_{\mathrm{x}}$ that forms an interfacial "third-body" material of easy shear. The coatings showed reduced sensitivity to air humidity and excellent wear resistance. Wear rates are improved by graded architecture (tuned with bias), ordered structures (promoted by heating) or C-incorporation $\left(\mathrm{WSe}_{\mathrm{x}} / \mathrm{W}_{2} \mathrm{C}\right.$ nanocomposite or alloyed WSeC). In conclusion, the tribological properties of tungsten selenide cannot be generalised but defined as a combination of chemical composition (Se/W ratio), structure (film morphology), adhesion to the substrate and environmental effects, besides of experimental testing conditions.

\section{Acknowledgements}

The Spanish MEC (projects no MAT2010-21597-C02-01; MAT2011-29074-C02-01 and CONSOLIDER FUNCOAT CSD2008-00023), and Junta de Andalucía P10-TEP67182 are acknowledged for financial support. Carmen Serra and CACTI facilities at the University of Vigo are also acknowledged for the XPS and nanoindentation measurements. 


\section{References}

[1] M.C. Simmonds, A. Savan, E. Pflüger, H. Van Swygenhoven, Mechanical and tribological performance of $\mathrm{MoS}_{2}$ co-sputtered composites, Surface \& Coatings Tecnology 126 (2000) 15-24.

[2] A. Nossa, A. Cavaleiro, N.J.M. Carvalho, B.J. Kooi, J. Th. M. De Hosson, On the microstructure of tungsten disulfide films alloyed with carbono and nitrogen, Thin Solid Films 484 (2005) 389-395.

[3] A. Savan, E. Pflüger, R. Goller, W. Gissler, Use of nanoscaled multilayer and compound films to realize a soft lubrication phase within a hard, wear-resistant matrix, Surface \& Coatings Technology 126 (2000) 159-165.

[4] S. Watanabe, J. Noshiro, S. Miyake, Tribological characteristics of $\mathrm{WS}_{2} / \mathrm{MoS}_{2}$ solid lubricant multilayer films, Surface \& Coatings Technology 183 (2004) 347-351.

[5] J.I. Oñate, M. Brizuela, A. García-Luis, I. Braceras, J.L. Viviente, Improved tribological behaviour of $\mathrm{MoS}_{2}$ thin solid films alloyed with WC, $9^{\text {th }}$ European space mechanisms and tribology symposium, ESA special publications 480 (2001) 257-262.

[6] A.A. Voevodin, J.S. Zabinski, Supertough wear-resistant coatings with 'chameleon' surface adaptation, Thin Solid Films 370 (2000) 223.

[7] S. Gangopadhyay, R. Acharya, A.K. Chattopadhyay, S. Paul, Composition and structure-property relationship of low-friction, wear resistant $\mathrm{TiN}-\mathrm{MoS}_{\mathrm{x}}$ composite coating deposited by pulsed closed-filed unbalanced magnetron sputtering, Surface \& Coatings Technology 203 (2009) 1565-1572.

[8] D.V. Shtansky, A.N. Sheveyko, D.I. Sorokin, L.C. Lev, B.N. Mavrin, Ph.V. Kiryukhantsev-Korneev, Structure and properties of multi-component and multilayer $\mathrm{TiCrBN} / \mathrm{WSe}_{\mathrm{x}}$ coatings deposited by sputtering of $\mathrm{TiCrB}$ and $\mathrm{WSe}_{2}$ targets, Surface and Coatings Technology 202 (2008) 5953-5961.

[9] S.V. Prasad, N.T. McDevitt, J.S. Zabinski, Tribology of tungsten disulfidenanocrystalline zinc oxide adaptive lubricant films from ambient to $500^{\circ} \mathrm{C}$, Wear 237 (2000) 186-196.

[10] T. Polcar and A. Cavaleiro, Review on self-lubricant transition metal dichalcogenide nanocomposite coatings alloyed with carbon, Surface \& Coatings 
Technology 206 (2011) 686-695.

[11] M. Evaristo, T. Polcar, A. Cavaleiro, Self-lubricant W-S-C nanocomposite coatings, Plasma Processes \& Polymers 6 (2009) S92-S95.

[12] T. Polcar, M. Evaristo, A. Cavaleiro, The tribological behavior of W-S-C films in pin-on-disk testing at elevated temperature, Vacuum 81 (2007) 1439-1442.

[13] D.V. Shtansky, T. B. Lobova, V. Yu. Fominski, S.A. Kulinich, I.V. Lyasotsky, M.I. Petrzhik, E.A. Levashov, J.J. Moore, Structure and tribological properties of $\mathrm{WSe}_{\mathrm{x}}$, $\mathrm{WSe}_{\mathrm{x}} / \mathrm{TiN}, \mathrm{WSe}_{\mathrm{x}} / \mathrm{TiCN}$ and $\mathrm{WSe} \mathrm{x}_{\mathrm{x}} / \mathrm{TiSiN}$ coatings, Surface \& Coatings Technology 183 (2004) 328-336.

[14]V. Yu. Fominski, V.N. Nevolin, R.I. Romanov, V. I. Titov, W. Scharff, Tribological properties of pulsed laser deposited $\mathrm{WSe}_{\mathrm{x}}(\mathrm{Ni}) / \mathrm{DLC}$ coatings, Tribology Letters 17 (2004) 289-294.

[15] T. Kubart, T. Polcar, L. Kopecky, R. Novak, D. Novakova, Temperature dependence of tribological properties of $\mathrm{MoS}_{2}$ and $\mathrm{MoSe}_{2}$ coatings, Surface \& Coatings Technology 193 (2005) 230-233.

[16] J.J. Hu, J.S. Zabinski, J.E. Bultman, J.H. Sanders, A.A. Voevodin, Structure characterization of pulsed laser deposited $\mathrm{MoS}_{\mathrm{x}}-\mathrm{WSe}_{\mathrm{x}}$ composite films of tribological interests, Tribology Letters 24 (2006) 127-135.

[17] V. Yu. Fominski, S.N. Gregoriev, J.P. Celis, R.I. Romanov, V.B. Oshurko, Structure and mechanical properties of W-Se-C/diamond-like carbon and WSe/diamond-like carbon bi-layer coatings prepared by pulsed laser deposition, Thin Solid Films 520 (2012) 6476-6483.

[18] S.N. Gregoriev, V. Yu Fominski, A.G. Gnedovets, R.I. Romanov, Experimental and numerical study of the chemical composition of $\mathrm{WSe}_{\mathrm{x}}$ thin films obtained by pulsed laser deposition in vacuum and in a buffera gas atmosphere, Applied Surface Science 258 (2012) 7000-7007.

[19] N. Guettari, J. Ouerfelli, J.C. Bernède, A. Khelil, J. Pouzet, A. Conan, Photoconductive $\mathrm{WSe}_{2}$ thin films obtained by solid state reaction in the presence of a thin nickel layer, Materials Chemistry and Physics 52 (1998) 83-88.

[20] C. Chiritescu, D.G. Cahill, N. Nguyen, D. Johnson, A. Bodapati, P. Keblinski, P. Zschack, Ultralow Thermal Conductivity in Disordered, Layered $\mathrm{WSe}_{2}$ Crystals, 
Science 315 (2007) 351-353.

[21] W.E. Jamison, S.L. Cosgrove, Friction characteristics of transition-metal disulfides and diselenides, ASLE Transactions 14 (1970) 62-72.

[22] B. Bhushan, B.K. Gupta, Handbook of Tribology-Materials, Coatings and Surface Treatments, McGraw-Hill, Inc, USA, 1991, pp. 51.

[23] W. C. Oliver, G. M. Pharr, An improved technique for determining hardness and elastic-modulus using load and displacement sensing indentation experiments, Journal of Materials Research 7 (1992) 1564-1583.

[24] M.D. Abad, M.A. Muñoz-Márquez, S. El Mrabet, A. Justo, J.C. Sánchez-López, Tailored synthesis of nanostructured WC/a-C coatings by dual magnetron sputtering, Surface \& Coatings Technology 204 (2010) 3490-3500.

[25] D. J. Mead, J.C. Irwin, Long wavelength optic phonons in $\mathrm{WSe}_{2}$, Canadian Journal of Physics 55 (1977) 379-382.

[26] J. Moser, F. Levy, Crystal reorientation and wear mechanisms in $\mathrm{MoS}_{2}$ lubricating thin-films investigated by TEM, Journal of materials research 8 (1993) 206 -213.

[27] T. Polcar, M. Evaristo, R. Colaco, C.S.Sandu, A. Cavaleiro, Nanoscale triboactivity: The response of Mo-Se-C coatings to sliding. Acta Materialia 56 (2008) $5101-5111$.

[28] S. El Mrabet, M.D. Abad, C. López-Cartes, D. Martínez-Martínez, J.C. SánchezLópez, Thermal evolution of $\mathrm{WC} / \mathrm{C}$ nanostructured coatings by Raman and in situ XRD analysis, Plasma Processes \& Polymers 6 (2009) S444-S449.

[29] A. Baserga, V. Russo, F. Di Fonzo, A. Bailini, D. Cattaneo, C. S. Casari, A. Li Bassi, C. E. Bottani, Nanostructured tungsten oxide with controlled properties: Synthesis and Raman characterization, Thin Solid Films 515 (2007) 6465-6469. 


\section{Figure captions}

Fig. 1. a) XPS general survey measured on WSe-1. b) Comparison of the Se/W ratios before and after surface cleaning with $\mathrm{Ar}^{+}$sputtering.

Fig. 2. a) XPS photoelectron spectra showing Se $3 d$ and $W$ ff (a) and C 1 s regions (b) for the four studied samples.

Fig. 3. SEM cross-section views of the $\mathrm{WSe}_{\mathrm{x}}$-based films together with their corresponding EDX chemical composition profiles measured along the film thickness.

Fig. 4. XRD patterns of the WSe $\mathrm{X}_{\mathrm{x}}$-based films.

Fig. 5. Raman spectra of the WSe $\mathrm{e}_{\mathrm{x}}$-based films.

Fig. 6. a) Hardness and Young's modulus values measured by nanoindentation. b) Dependence of the hardness versus the penetration depth for the $\mathrm{WSe}_{\mathrm{x}}$-based films.

Fig. 7. Dependence of the friction coefficient measured in ambient air for a complete series of $\mathrm{WSe}_{\mathrm{x}}$-based films with variable $\mathrm{Se} / \mathrm{W}$ content

Fig. 8. Evolution of the friction coefficient of WSe-2 film vs. number of sliding cycles for ambient air and dry nitrogen atmospheres.

Fig. 9. Optical micrographs taken from ball and film wear track counterfaces after friction tests in ambient air and dry nitrogen. 
Fig.10. Average friction coefficient and wear rate values measured for the $\mathrm{WSe}_{\mathrm{x}}$-based films in ambient air.

Fig. 11. Average friction coefficient and wear rate values measured for the $\mathrm{WSe}_{\mathrm{x}}$-based films in dry nitrogen.

Fig. 12. Raman analysis of the worn surfaces after testing in ambient air: a) film wear tracks; b) transferred material onto the ball.

Fig. 13. Raman analysis of the worn surfaces after testing in dry nitrogen: a) film wear tracks; b) transferred material onto the ball. 


\section{WSe-1}

After sputtering

Initial

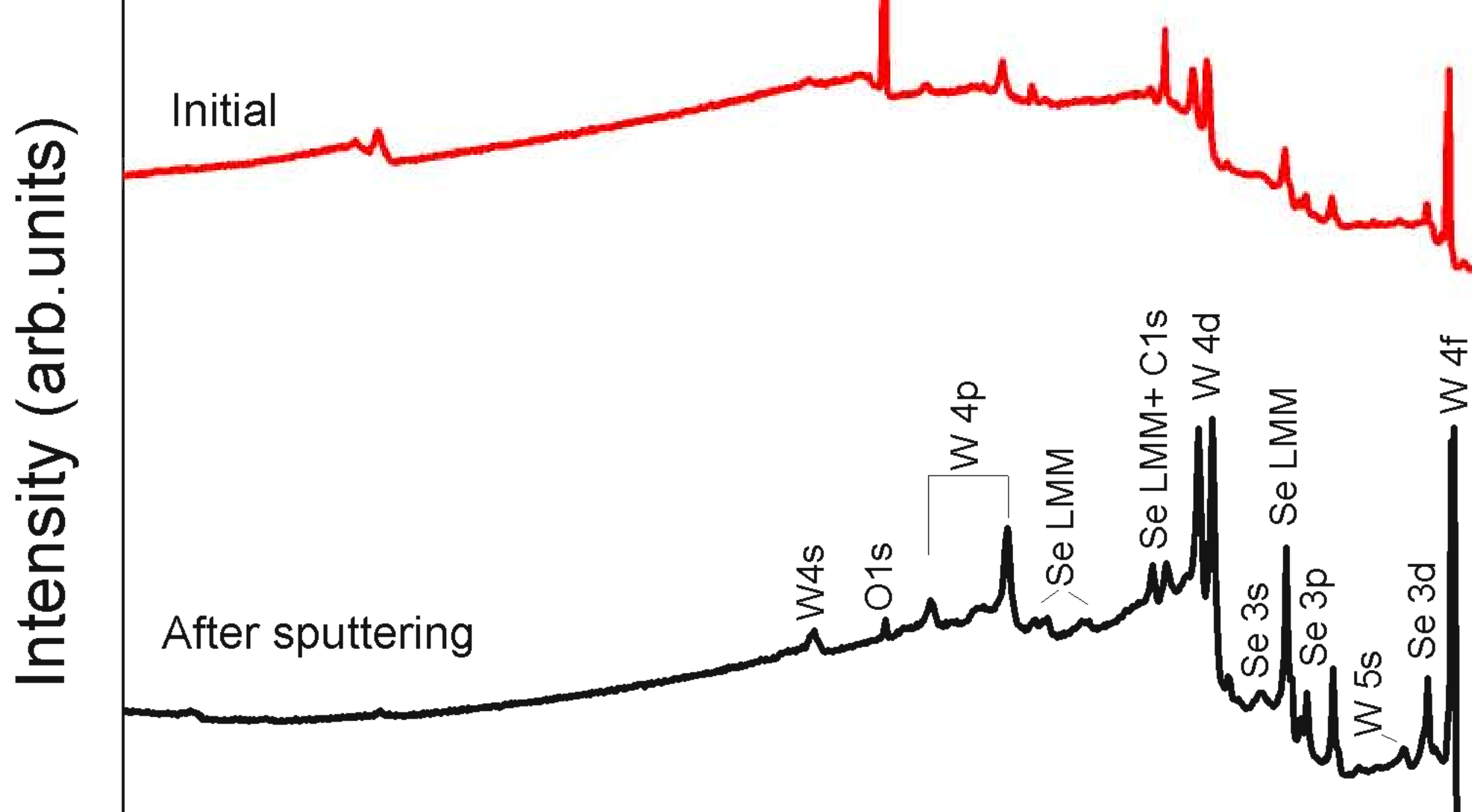




\section{b)}

C1s

WSeC

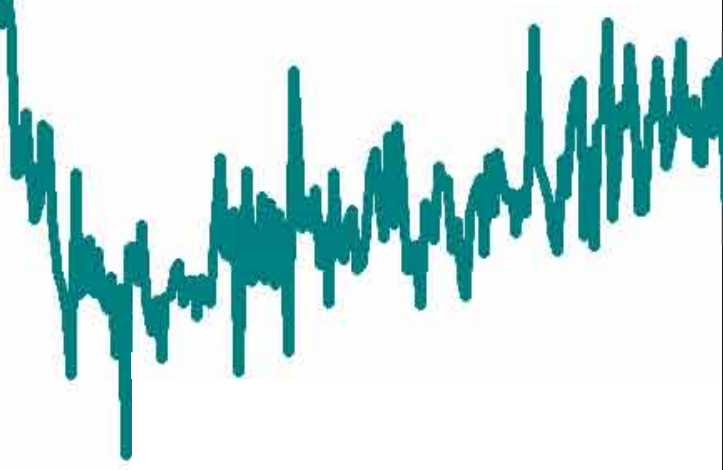




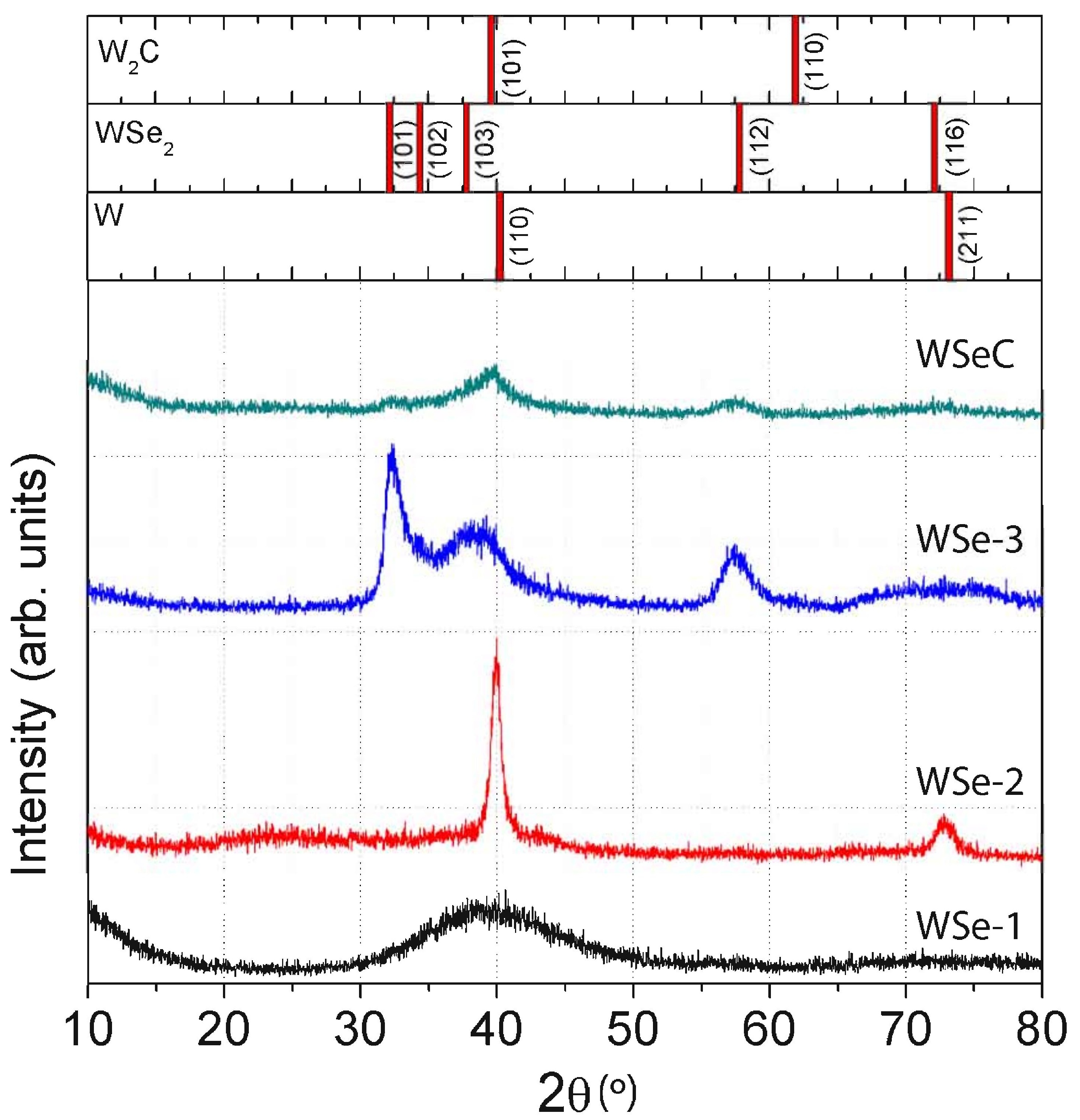




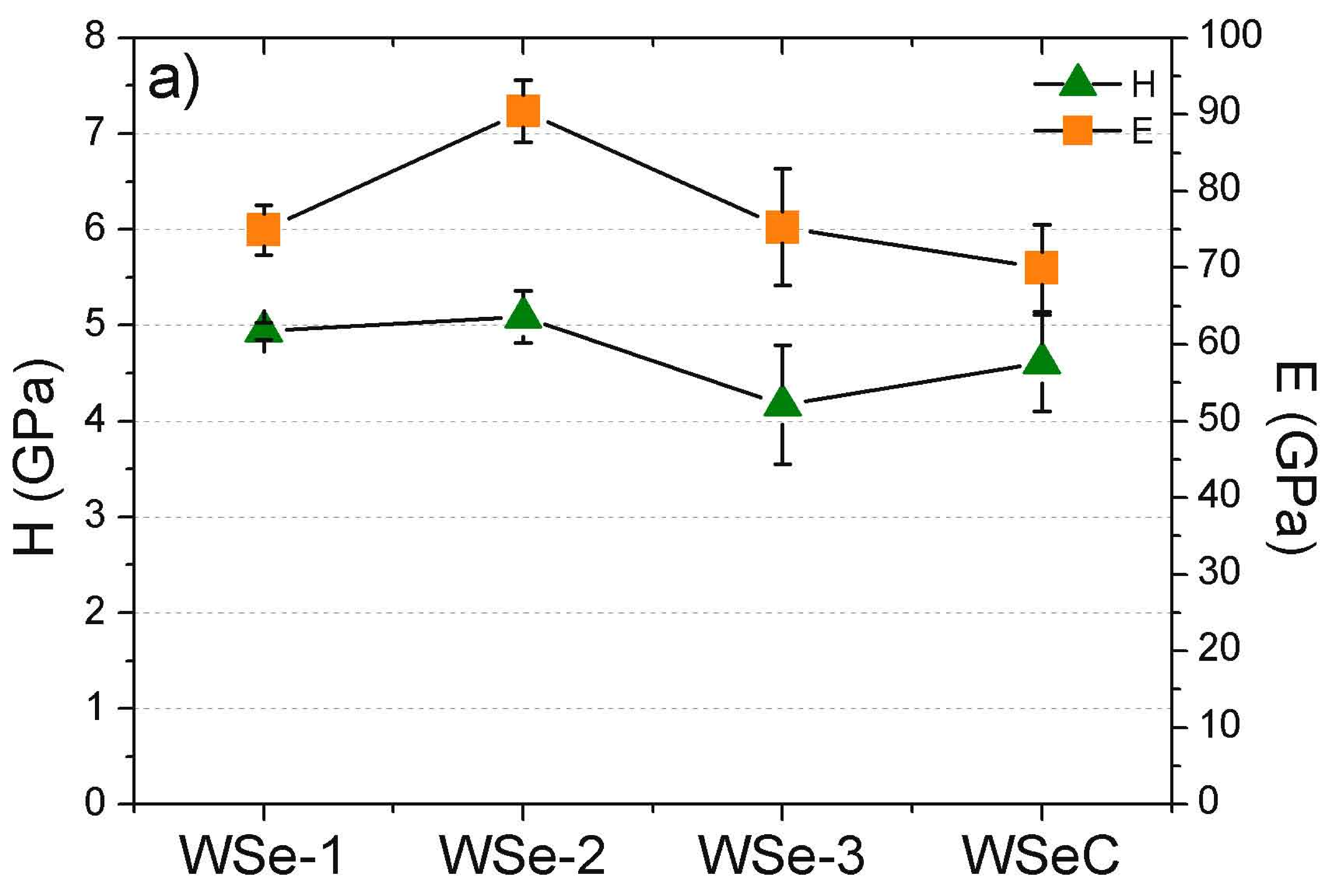




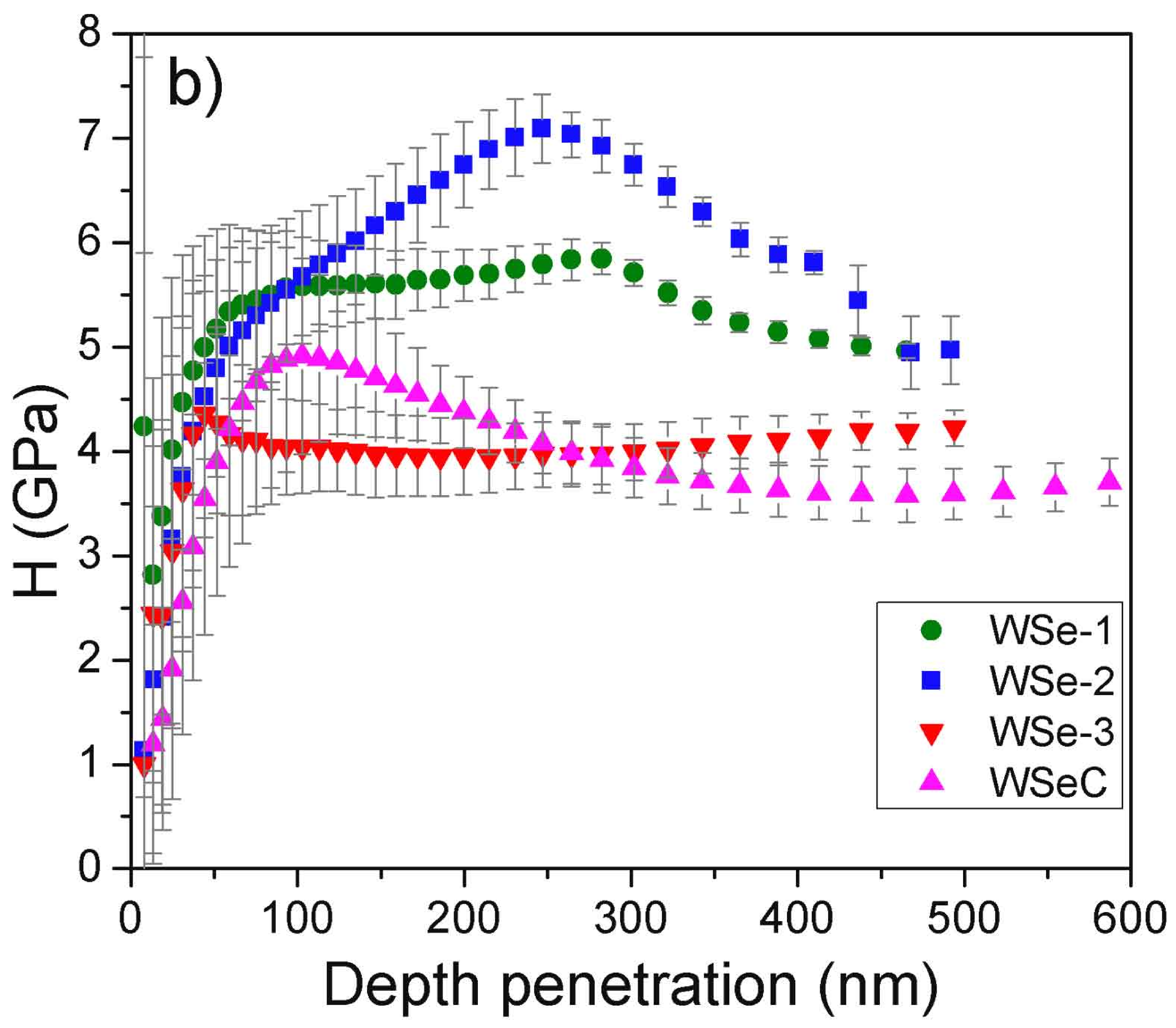




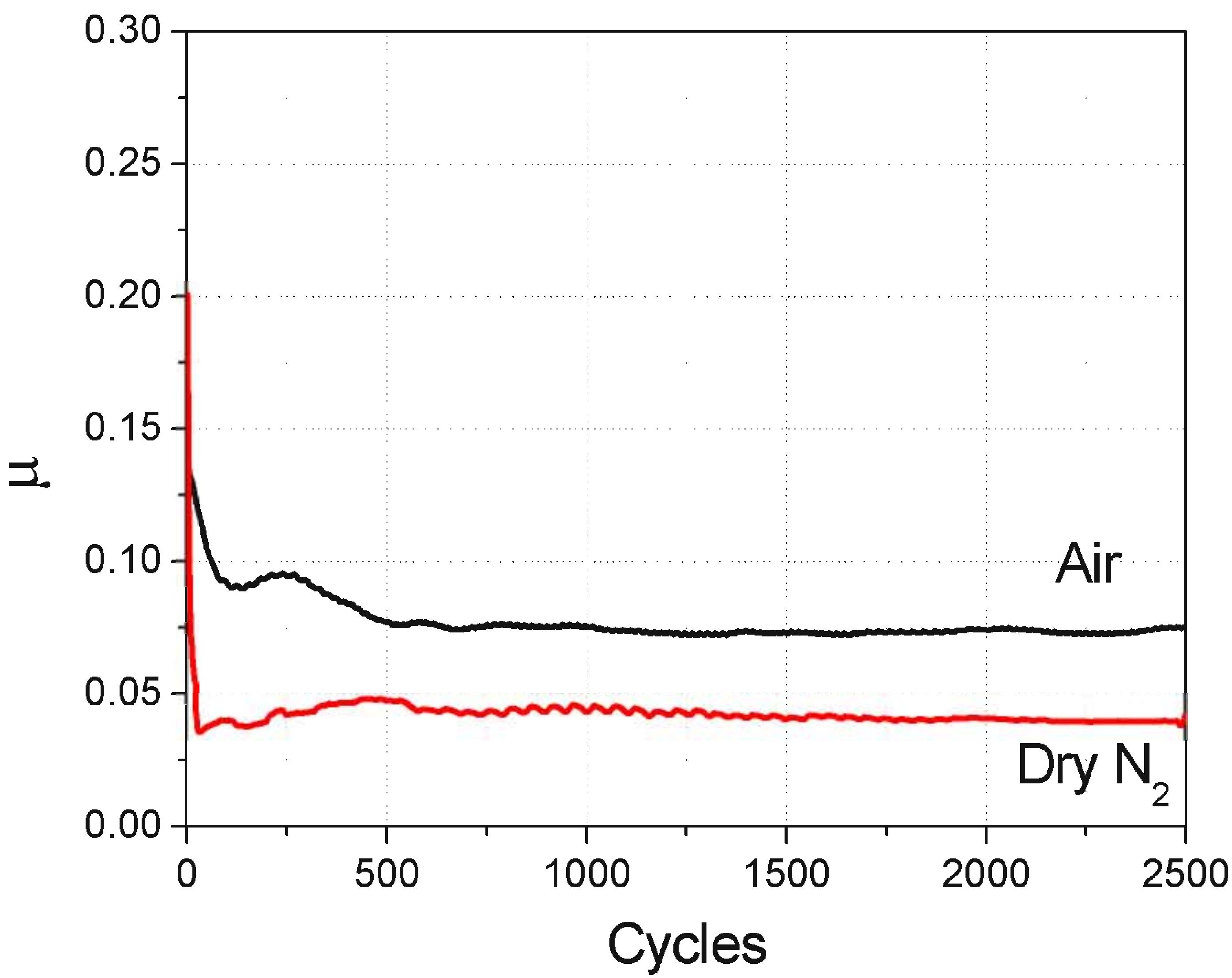




\section{Ball}
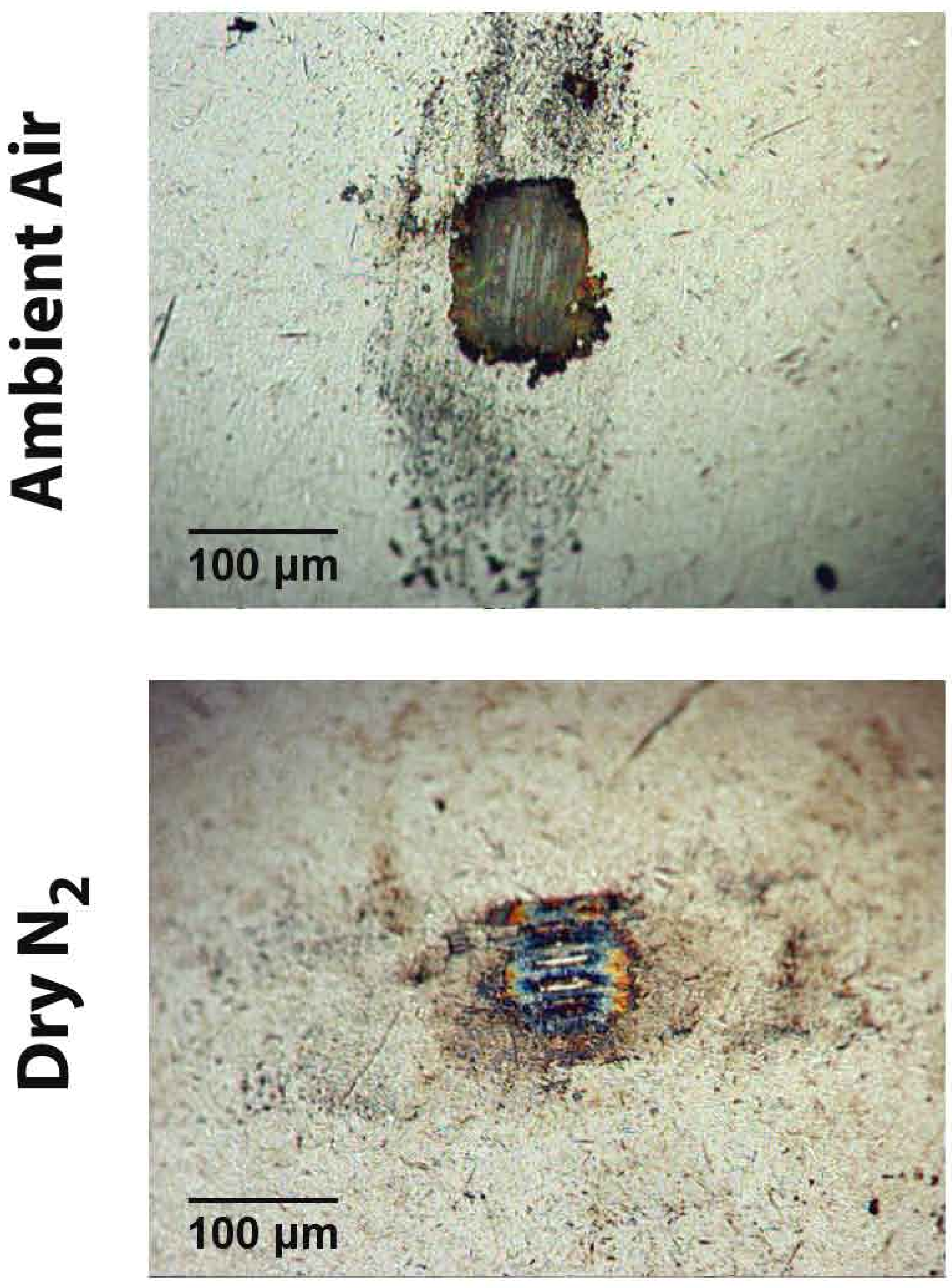

Track
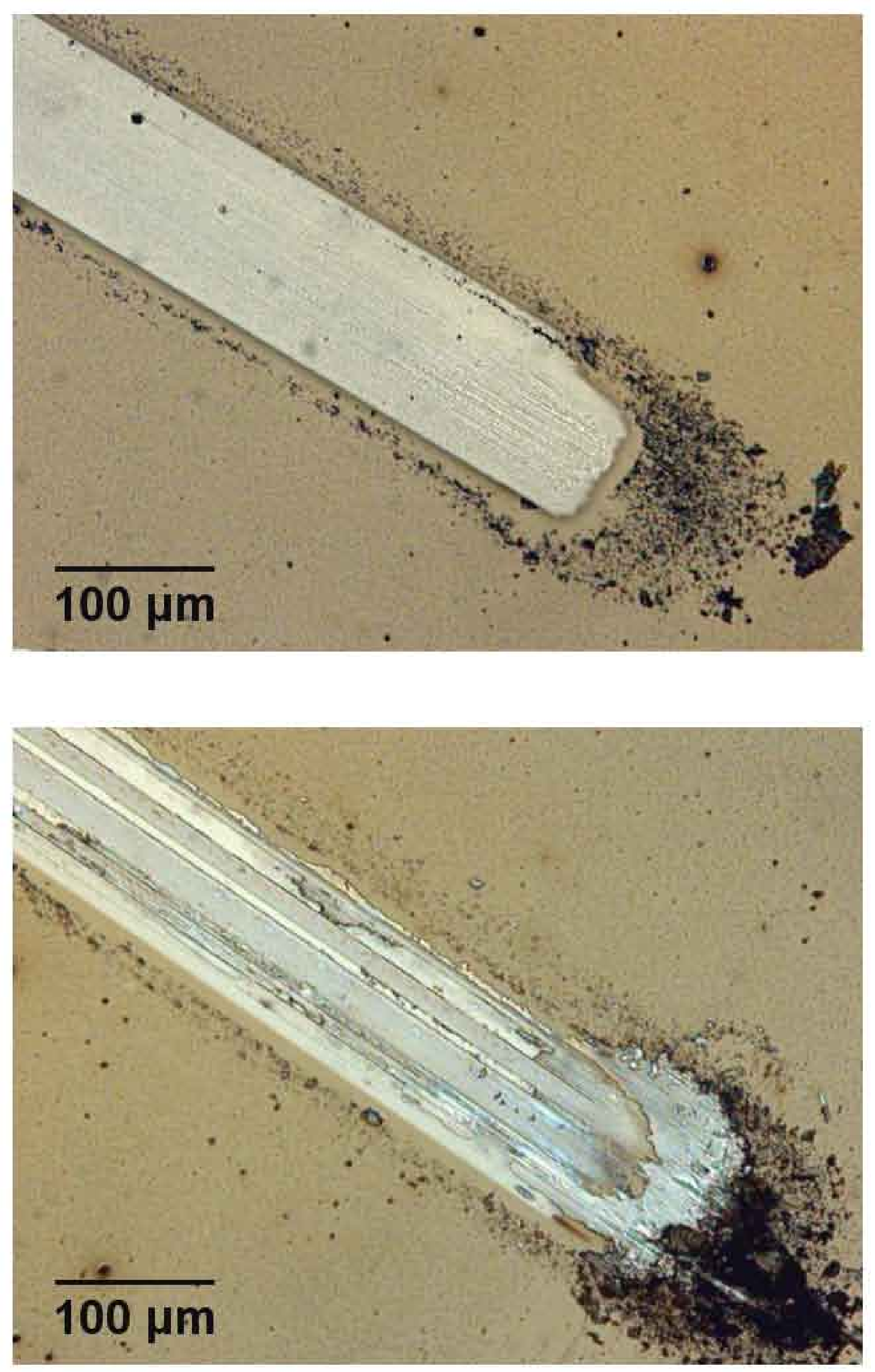


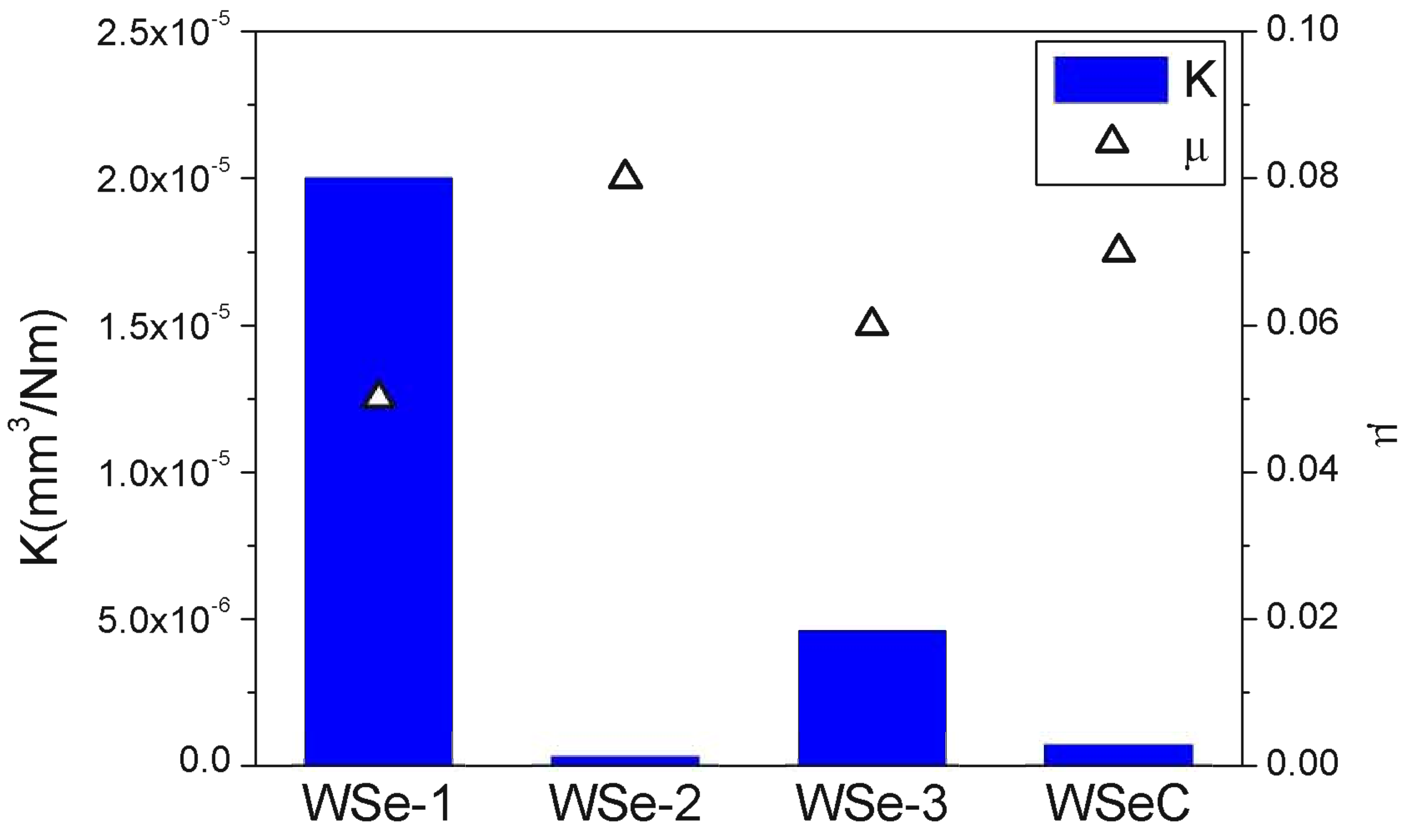




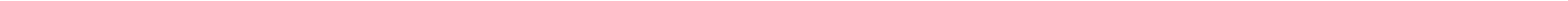




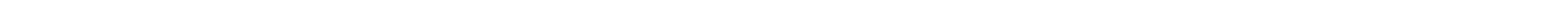




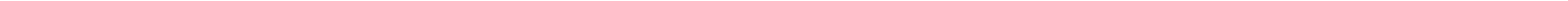

